\title{
LAS FORMAS DE GERUNDIO Y GERUNDIVO
}

The origin of Latin gerunds and gerundives has not yet received a satisfactory solution. The author, following a suggestion of Thurneysen, proposes that gerundives were the origin of gerunds, because there were common to Latin and Italic dialects. The gerundives, on its side, are simply an Italic evolution of the middle Indoeuropean participle ending in -menos.

La cuestión del origen de las formas verbales en -ndo es un problema del que pudiera decirse lo mismo que sobre el de la naturaleza del acento latino; es decir, que ha sido tan discutido como en otros tiempos fue el de la cuadratura del círculo. Pero ya Wackernagel vio (Vorlesungen I, p. 281) que las hipótesis formuladas sobre él hasta su época eran completamente insatisfactorias. $Y$ de ahí que, tras estudiar ampliamente los otros participios, al llegar a las formas en -ndo, renunció a ocuparse de ellas diciendo expresamente que, ante la imposibilidad de establecer de manera segura el origen de las mismas, se consideraba incapaz de abordar su estudio sintáctico. Ahora bien, aun después de Wackernagel ha seguido acumulándose sobre el tema una bibliografía inmensa, de la que puede verse un resumen en StolzLeumann, $H$. Gr.6, pp. 331-332 ${ }^{1}$. Pero como en otros muchísimos casos, ha ocurrido que lo que no lograron aclarar los Neogramáticos (en las décadas del 1870 al 1890), ha sido imposible aclararlo después, a pesar de todos los esfuerzos que se hayan hecho. $O$ lo que es lo mismo, que la Gramática Histórica, a pesar de sus pretensiones de rigor y de seguridad en sus conclusiones, es una ciencia que en cierto modo nació paralítica. Que nació paralítica, y que así ha seguido siendo y seguirá siéndolo hasta el final de los siglos, mientras que no se la desprenda de los presupuestos sobre los que se la quiso fundar.

1 Por su extensión merece destacarse el amplio estudio de Aalto, Untersuchungen iber das lateinische Gerundium und Gerundiuum, Uppsala 1949; aunque es muy poco lo que de nuevo aporta a la cuestión. 
En todo caso es claro que en concreto en el problema del origen del -ndo apenas se ha superado el callejón sin salida en que Wackernagel lo encontró. Esto lo prueba la multitud de hipótesis que se han venido emitiendo sobre él. Y lo reconocen tanto Stolz-Leumann, $H$. Gr.6, pp. 331 y 584, como Schmalz-Hofmann-Szantyr, Lat. Synt., p. 368; quienes sólo dan como indudable la relación del adjetivo en -ndus (Gerundivo) con el sustantivo en -ndi, -ndo, -ndum (Gerundio), pero confesando que tanto el origen de la formación como la prioridad de una de las formas sobre la otra son cuestiones oscuras. Así es que no voy a analizar y discutir aquí las innumerables hipótesis que sobre estos hechos se han propuesto.

Yo lo que sí creo, frente a estos autores, es que sobre uno de los puntos claves del problema (a saber, el de la prioridad de las formas) sí que puede deducirse una conclusión suficientemente fundada. Pues da la casualidad que del gerundivo existen formas en los dialectos, en los que no quedó el menor rastro del gerundio. Así por ejemplo osc. úpsannam 'operandam', sakrannas 'sacrandae'; umbr. pihaner 'piandi', anferener 'circumferendi'. A esto han solido replicar los partidarios de la prioridad del gerundio que la falta de éste en los dialectos pudiera deberse a la escasez de nuestra documentación sobre el O-U. Pero esta mayor antigüedad del gerundivo sobre el gerundio está confirmada por otros varios indicios. A saber, en primer lugar porque fue el que dio origen a diversos derivados sin duda antiguos, los en -cundus y en -bundus. $\mathrm{Y}$ porque a su vez dio origen a diversos adjetivos, desprendidos en parte del tema verbal, y que por lo tanto siguieron la evolución fonética regular. Lo que demuestra también su origen relativamente antiguo. Así secundus, oriundus, y Kalendae < ${ }^{*}$ Kalanda (sc. luna), y a lo que creo crepundia *crepundus «sonajero, bola que se colgaba al cuello de los niños pequeños, con objetos dentro para hacer ruido y entretenerlos», crepitacula oblectamenta, qualia infantibus dari solent, que dice el Thesaurus ${ }^{2}$. Por otra parte se ve que la sustantivación de

2 A crepundia lo ha querido separar Leumann, Kl. Schr., p. 193 de crepāre, y considerarlo un etrusquismo o un derivado de un supuesto ${ }^{*} g^{*} r e p$, relacionado posiblemente con la raíz de $\pi \rho \varepsilon \tilde{\varepsilon} \varepsilon$ ' 'conviene'. Pero por su forma crepundia tiene un aspecto típico de palabra latina. Y semánticamente se adapta perfectamente al sentido de crepare 'hacer ruido'. Y por otra parte en etrusco no hay ningún elemento que remita a una forma como ésa, ni $\pi \rho \varepsilon \varepsilon \varepsilon \iota$ parece derivar de * $g^{u} r e p$ sino de *prep- sin relación semántica ninguna con crepäre ni con crepundia (cf. Hjalmar Frisk, Gr. etym. Wörterbuch). Yo me inclino pues a pensar (con ErnoutMeillet y Walde-Hoffmann) que crepundia debió salir de crepāre. Me inclino a pensarlo, porque entiendo que crepāre, -ui, -itum debió proceder de un tema consonántico *crep-, como strep-ere y como son-o, -is, -ere, posteriormente sono, $\bar{a} s$, -äre. Con lo cual crepundia se explica sencillamente como un derivado anterior 
primitivos adjetivos fue un fenómeno general en toda clase de adjetivos, y en particular en los adjetivos verbales en -tos y en -ns. Mientras que del paso inverso, la conversión de sustantivos en adjetivos, no quedaron en latín más que casos rarísimos: uetus 'viejo': gr. Ětos 'año', ūber 'fértil': gr. oũ $\theta \propto \rho$ 'ubre', frūgi 'frugal' (dat. de frux 'ser de provecho'). Lo cual lleva igualmente a la prioridad del gerundivo sobre el gerundio.

No sólo esto, sino que en las lenguas es una ley general que las formas que tienden a generalizarse y sobrevivir suelen ser las secundarias, posteriores respecto a las paralelas más arcaicas, que suelen tender a desaparecer. Ahora bien la situación del gerundivo y del gerundio suele ser un poco compleja, porque ya en la época de Plauto el gerundio estuvo más extendido que el gerundivo. Pero esto se debió a causas diversas. Una por ejemplo el que Plauto estuvo ya muy influido por la lengua del pueblo, en la que predominó, como se ve por el desarrollo posterior, la tendencia al gerundio. Y otra el que el gerundio, una vez surgido, tuvo siempre un campo de uso mucho más amplio que el gerundivo, puesto que permitía aplicarlo a toda clase de verbos, transitivos e intransitivos, mientras que el gerundivo sólo podía emplearse con verbos transitivos, en los que era posible la construcción pasiva. Pero en los clásicos, que sin duda representan la construcción ide. más pura, el uso del gerundivo en vez del gerundio con acusativo, en los verbos que admitían la doble construcción, estuvo mucho más desarrollado que el del gerundio. Hasta tal punto que los clásicos por excelencia (Cicerón y César) sólo conocen en el dativo y el acusativo la construcción gerundiva. Cuando el gerundio en dativo y acusativo con acusativo complemento se hace más frecuente es en los autores de la época imperial. Donde en los mismos clásicos por excelencia penetra alguna vez la construcción con gerundio es en el ablativo y en genitivo. Así Cic., Ad Att. X 4, 6; consilium relinquendi Italiam; y Cic., Diu. 60: iniurias ferendo maiorem laudem quam ulciscendo mereri. Pero se trata de un uso infinitamente más reducido que el del gerundivo. Téngase en cuenta que en Cicerón frente a 587 pasajes con la construcción gerundiva sólo hay 24 con gerundio en genitivo; y en César frente a 280 con gerundivo sólo 7 con gerundio ${ }^{3}$. Y de un uso que en el caso del gerundio en genitivo tuvo una causa primordial clara. Es que la construcción del gerundivo, cuando éste iba apuesto a un

\footnotetext{
al crepāre. Lo mismo que el paso de *crepere a crepäre se explica por un influjo analógico de sonäre. En cuanto al paso de sonere a sonäre debió ser una asimilación del tema radical son-ere a los verbos denominativos en -äre (pugnus: pugnäre, seruus : seruäre, etc.).

3 Cf. Kühner-Stegmann, Lat. Gramm. p. 735.
}

$\mathrm{XLIX}, 2 .^{\circ}-4$ 
nombre en plural, obligaba a amontonar los finales en -orum, -arum. Lo cual daba origen a expresiones pesadas, en cierto modo cacofónicas, que a los latinos les resultaron sin duda violentas. Lo cual no quita que excepcionalmente, en casos aislados, tales construcciones se diesen. Así Pl., Capt. 889: liberorum quaerundorum causa; y Cic., Or. 20, 68: licentiam faciendorum iungendorumque uerborum; y Cic., Catil. I 37: non tam sui conseruandi quam tuorum consiliorum reprimendorum causa; y por ej. Lex agr. II 14, 37: audacia decemuirali corrumpendarum tabularum fingendorumque senatus consultorum; ibid. II 34: omnes prouincias obeundi, liberos populos agris multandi, regnorum uendendorum summa potestas datur. Pero es evidente que en general a los latinos les resultó malsonante tal construcción y que trataron de evitarla. Y así se explica el hecho curioso de que entre los clásicos fue la construcción con gerundio en genitivo la que penetró algo más, a pesar de que la construcción de suyo más popular fue con gerundivo. En este aspecto es muy significativo que aún en los clásicos la construcción con gerundio suele darse sobre todo cuando el complemento del gerundio es un plural: tempus tela iactandi experiundi animos causa; mucho más raramente cuando el complemento era un singular: consilium relinquendi Italiam. Es pues evidente que los literatos latinos sintieron la tendencia a evitar la repetición del -orum, aunque alguna vez aislada el arraigo de la construcción del gerundivo les llevase a admitirla incluso a Cicerón ${ }^{4}$. Lo que desde luego se advierte es que a partir de la época postclásica, incluso en autores literarios, cada día se va extendiendo más el gerundio a expensas del gerundivo, que al final terminó desapareciendo en las lenguas romances. Señal inequívoca de que la tendencia al gerundio procedía de la lengua popular. Todo pues indica que fue la forma más antigua la que desapareció, y la secundaria la que sobrevivió. Esto lo vio ya Sommer, IF Anz. 13, 1902, p. 44 y $H b$., p. 592.

$\mathrm{Y}$ aparte de esto a mí me parece a su vez imposible que sintácticamente pueda explicarse el paso del gerundio al gerundivo. Pues lo más que han podido decir los partidarios de esa hipótesis es que el gerundivo debió salir de construcciones con gerundio más complemento directo, en las que éste se asimiló mecánicamente al caso del gerundio. Así Schmalz-Hofmann-Szantyr, Lat. Synt., p. 374. Es decir, que giros como lucis das tuendae copiam habrian salido de otros anteriores como lucis das tuendi copiam. Genitivos pues (los de lucia y tuendi), que en

4 Esto lo notó ya Kühner-Stegmann, loc. cit.; y lo ha subrayado Ad. Hahn, loc. cit. en n. 5. 
principio habrían actuado cada uno de por sí independientemente, como complementos de copiam, pero que luego se habrían asimilado. Lo cual significa que deberían haber tenido un sentido como «la facultad de ver, la facultad de la luz». Pero a mí me parece que construcciones como ésas carecen intrínsecamente de sentido. $Y$ en realidad y a pesar de lo que se diga, tampoco tienen correspondencia en ninguna lengua ide. Pues los hechos que se citan como análogos de ai., en particular, algunos infinitivos del ai. y sobre todo del hitita ${ }^{5}$, son formas morfológica y fonéticamente distintas, y sin relación ninguna directa con las en -nd- exclusivas del latín.

$\mathrm{Y}$ de hecho en latín se ve que de ese uso concreto del gerundio en genitivo, que es el único en que se apoya tal hipótesis, no quedaron más que dos ejemplos antiguos: Pl., Capt. 1008, lucis das tuendi copiam, y Enn., Scaen. 248: nauis incohandi exordium. De lo que ciertamente se dan algunos ejemplos más, por supuesto no muy numerosos, es de otra construcción, en apariencia parecida, pero con un rasgo muy peculiar, que a mi juicio las caracteriza como casos aparte. Me refiero a casos como Pl., Capt. 852: istorum nominandi copia; en los que el sustantivo apuesto al gerundio en genitivo va no en singular sino en plural. Giro que, además de alguna vez en Plauto, se da en algunos autores arcaicos como Ter., Heaut. 29: nouarum (sc. Fabularum) spectandi causa, y en Lucr. V 1225: poenarum soluendi potestas, y en Varr., y sobre todo en Cic., De inuent. II 25: exemplorum eligendi potestas; Phil. 5, 6: agrorum suis latronibus condonandi, etc., y luego, bajo el influjo sin duda de Cicerón, en algunos autores posteriores. Este giro se suele interpretar como un arcaísmo dándolo como una herencia del ide. Pero, si se prescinde de Lucrecio, es claro que en los demás autores en que se da, y sobre todo en Cicerón, que fue el que más lo usó, es inconcebible pensar en un arcaísmo. La contraprueba más clara nos la ofrece el que en un autor tan típicamente arcaizante como Salustio nunca se dé. Evidentemente hay que concluir que el giro tuvo que proceder del latín, y deberse a alguna causa especial surgida en latín. $\mathrm{Y}$ efectivamente se ve que el giro sólo aparece en construcciones con el nombre apuesto en plural. Es decir, en construcciones que hubiesen dado la acumulación de finales en -orum, evitada en lo posible por los autores latinos. Ahora bien, la salida natural ante esto, y que en general eligieron los literatos (incluso los clásicos) fue acogerse al genitivo más acusativo, muy propagado en la lengua popular. Pero algunos autores como Cicerón, que estaban especialmente familiarizados con el gerun-

5 Cf. Ad. Hahn, TAPhA 74, 1943, p. 268. 
divo, encontraron al parecer cierta dificultad en adaptarse al uso más popular y prefirieron una tercera vía (el exemplorum eligendi potestas), como un compromiso entre las dos tendencias. Es así como yo interpreto esa construcción, que luego adoptaron otros autores por influjo sin duda de Cicerón.

Es decir, que de casos como lucis das tuendi copiam no quedan en latín antiguo más que los dos ejemplos citados ${ }^{6}$. Dos ejemplos como he dicho sin correspondencia en las otras lenguas ide. Y claro está que sólo dos ejemplos de este tipo no creo que sean base suficiente para sostener la hipótesis de que esa clase de construcción con el gerundio fuese anterior al gerundivo. Y menos aún cuando morfológicamente todo parece llevar a la hipótesis opuesta. Por lo tanto yo lo que deduzco es que tales ejemplos tuvieron que ser, o una grafía equivocada en vez de tuendai, incohandai; o una falsa lectura de tuende, incohande; o tal vez más bien una corrección arbitraria de algún editor latino tardío, bajo el influjo de los casos como exemplorum eligendi potestas, o poenarum soluendi tempus, etc. Lo cual significa que a partir del gerundio es imposible explicar el gerundivo.

Frente a esto es claro que el sentido pasivo que hay que suponer en el gerundivo se explica sencillamente sobre el supuesto de que la forma en -ndo, como todo lleva a pensar y luego indicaré, fue un participio medio. Pues según es sabido, las formas medias en latín, lo mismo que en griego, tendieron a evolucionar a un sentido pasivo: «lo que se está haciendo», o «se ha de hacer», o «debe hacerse». Por otra parte se ve que en general en las lenguas ide. los participios admitieron un uso predicativo muy próximo al infinitivo. Así el de presente activo: uideo rure redeuntem senem; o quem (ego) huc aduenientem conspicor; o quos canentes obstupuit; o audit pueros canentes; o Poliphemum Homerus cum ariete colloquentem facit, etc. $\mathrm{Y}$ el de pasado pasivo: nuntiant o dicunt hostes uictos, o urbem captam, dirutam, incensam, o Ciceronem consulem creatum; o milites gaudent uictoria parta; o facto opus est, o cinere eruto opus est, etc. Expresiones éstas especialmente significativas, pues parece que fue sobre participios en acusativo de este tipo sobre los que se formaron los infinitivos pasivos de pasado: nuntiant o dicunt urbem captam, o incensam o dirutam esse; Ciceronem consulem creatum esse, etc. $\mathrm{Y}$ así igualmente el gerundivo en -ndus: dat puerum educandum; aurum seruandum dedit; hunc

6 Para el caso no significa nada algún otro que pudiera citarse ya fuera del periodo latino, como la Vita Radegudae 8, 20: adipiscendi uitae caelestis commercia; sin duda una imitación torpe de giros como exemplorum eligendi potestas de Cicerón. 
ad te diripiendum adducimus; quae utenda uasa semper uicini rogant; curat pontem faciendum o reficiendum; agrum colendum habebat; tradit onera portanda, etc. Construcciones éstas doblemente interesantes, porque su equivalencia a los infinitivos es todavía más visible que en los casos anteriores; y porque las expresiones admitían ser interpretadas indistintamente con un sentido activo o pasivo.

Lo que se ha objetado a veces contra esta hipótesis (así SchmalzHofmann-Szantyr, Lat. Synt., p. 371) es que el uso predicativo del gerundivo en acusativo todavía en Plauto está poco desarrollado, al menos tras do. Pero el número de verbos tras los que se da (adduco, peto, rogo, conduco, loco Pl.; habeo, propino, curo, Ter., Cic., Caes.) es bastante numeroso para considerarlos herencia del ide. Y por lo demás el grupo continuó aumentando con otros nuevos en los clásicos (curo, habeo, praebeo, concedo, defero, denoto, posco, suspicio, uoueo, mitto, trado, relinquo, etc.). Y no dejó de aumentar en los autores posteriores. Lo que pudiera dudarse es si en algunos de estos casos más tardíos no se trataría más bien de infinitivos pasivos con sujeto en acusativo. Hipótesis sin duda posible en casos como Oros., Hist. IV 3, 5: hoc facinus ... puniendum; ... consuli iussum est; y Bell. Hisp. 33, 3: cenam adferri ... imperauit, item optimis insternendum (sc. se) uestimentis. Pero lo cierto es que a su vez el infinitivo futuro pasivo no parece que pudiese ser más que un desarrollo de gerundivos predicativos. Algo así como, según hemos dicho, el infinitivo pasivo de pasado no debió ser más que un desarrollo del uso predicativo correspondiente del adjetivo en -tos. Es decir, todo lleva a pensar que amandum, legendum esse, etc. no salieron más que de escuetos gerundivos predicativos. Es decir, de casos como censet, credit, putat, statuit, dicit ... Carthaginem delendam, o coloniam deducendam, o exercitum mittendum o legatos reuocandos, o bellum gerendum, a los que posteriormente se les añadió el esse. Lo cual constituye una prueba de la gran antigüedad y extensión del gerundivo predicativo. $\mathrm{Y}$ en último término la prueba definitiva de que el -ndus predicativo en acusativo venía de una época muy antigua, por lo menos tan antigua como el itálico, es que se dio en los otros dialectos itálicos; en concreto en ejemplos como osco úpsannam deded, upsann $\langle n u\rangle$ deded, etc. Y naturalmente que una vez creada la formación, no tiene nada de particular que se la llevase a los casos oblicuos; lo mismo que se llevó la paralela con -tos: facto opus est; uictoria parta gaudent; dolent sanguine fuso, etc.

Y a partir de esta base era muy fácil el paso del gerundivo al gerundio. Pues sin duda el gerundivo proporcionaba un instrumento morfológico precioso, en cuanto que permitía el uso del infinitivo en los 
diversos casos de la flexión. Se comprende pues que a pesar de su sentido en principio pasivo se tendiese a llevarlo a toda clase de verbos. Por ejemplo, en primer lugar a los neutros o intransitivos, que por naturaleza carecían de la construcción pasiva, como pugnandi, ludendi, nocendi, fugiendi, nascendi, moriendi, etc. Y claro está que a partir de éstos era a su vez natural que se le extendiese a los verbos transitivos, en aquellos casos en que por cualquier razón las formas activas se usaban sin complemento, como tempus amandi, legendi, scribendi, discendi, docendi, soluendi, persequendi, etc. Así ya Sommer, Hb.3, p. 592. Casos todos en los que el gerundivo, al no tener punto de referencia, de adjetivo que era quedaba convertido en un sustantivo; y que de acuerdo con el uso del infinitivo presente debió constituirse sobre la forma neutra del gerundivo.

Ahora bien, en latín el complemento normal de los verbos transitivos activos, cuando lo llevaban, fue el acusativo, lo mismo en las formas personales que en los infinitivos. No tiene pues nada de extraño que, afirmada la conciencia de que los gerundios equivalían sintácticamente a infinitivos, por analogía se acomodase su construcción a esta concepción; y que, paralelo al uso heredado con gerundivo (legendi libri, tuendae lucis, bello gerendo, etc.), apareciese otro nuevo con expresiones como legendi librum, tuendi lucem, bellum gerendo, etc. Sobre las alternativas y vicisitudes de ambas tendencias a lo largo de la historia no pretendo entrar aquí en detalles. Lo único que me interesa destacar es que la transformación del gerundivo en gerundio se incubó y fue obra sobre todo de la lengua popular. La prueba es que en las lenguas romances no quedó la menor huella del gerundivo; lo único que sobrevivió fue el gerundio. Todo pues nos obliga a suponer que en su origen las formas en -ndo no pudieron ser más que adjetivos. Así ya Persson, De origine ac ui primigenia gerundi et gerundiui, Uppsala 1900; y de acuerdo con él Sommer, IF Anz. 13, 1902, p. 44. Es ésta la base sobre la que hay que plantear el problema de su etimología.

El punto más ocuro que sobre ese supuesto se nos presenta es precisamente el etimológico. Porque de las formas en -ndus no parece que haya correspondencia en ninguna de las lenguas ide. fuera del itálico. El hecho es a primera vista tan evidente, que Aalto, el autor que más a fondo ha estudiado en época más reciente la cuestión, loc. cit., llegó a pensar si no se trataría de una forma preide. Hipótesis por supuesto inconcebible, ya que en los sistemas verbales de las lenguas ide. no parece que se diesen préstamos de otras familias lingüísticas. Aparte de que tampoco fuera del ide. hay indicios de las formas en -ndo. $\mathbf{Y}$ desde luego Aalto no pudo justificar su sospecha con ninguna prueba 
positiva. Lo que ya entrevió Havet, $M S L 6,1884$, p. 232, fue que la formación en -ndus pudiera relacionarse con los participios medios del


toc. -mana. Hipótesis que luego trataron de rehabilitar, por una parte Thurneysen en $K Z 26,1883-84$, p. 303 ss., y posteriormente en $K Z 30$, 1890-91, p. 493, y por otra Bréal, $M S L$ 18, 1912-14, p. 180. E hipótesis que se compagina perfectamente con el hecho de que el -ndus se dio en una multitud de verbos deponentes, es decir con un sentido medio: oriundus, uoluendus, secundus, nascendus, moriendus, labundus, etc. Sentido del que era natural se pasase al pasivo «lo que se está haciendo, se va a hacer o se debe hacer", que fue el que con el tiempo tendió a adquirir el -ndus. Pues en latín fue ese sentido pasivo, en el que desembocaron en general las formas medias. No sólo esto, sino que en los verbos radicales y en los en -io de la tercera y cuarta conjugación el -ndus originariamente tuvo una forma -undus, que se adaptaba perfectamente al $-\delta \mu \varepsilon v o \varsigma$ de los participios griegos. Es decir, que en una serie de aspectos tal hipótesis presenta una apariencia seductora. Y de ahí que el mismo Sommer, IF, loc. cit., acercándose a la hipótesis de Havet y de Thurneysen, locs. cits., pensó que el -ndus fue un sufijo que había asumido los valores del $-\mu \varepsilon v o$ s. Que los había asumido, porque él, ante la creencia de que fonéticamente era imposible el paso -menos > -ndus, creyó con Persson, loc. cit., que el -ndus fue un sufijo de la época preétnica. Hipótesis como he indicado inconcebible, por cuanto que el -ndus sólo se da en itálico. Y que de hecho Sommer, lo mismo que Persson, no pudo justificar, ni por lo demás dar la razón de por qué el -ndus habría asumido la función del -menos. Pero la afinidad semántica intima entre el $-\mu \varepsilon v$ o y el -ndus la vio certeramente Sommer.

El problema al parecer insoluble dentro de las ideas admitidas es cómo de -menos podría haberse pasado a -ndus. Y el hecho es que los partidarios de tal hipótesis no pudieron justificar con ningún argumento sólido el supuesto paso. Ni Havet, que ni siquiera tuvo en cuenta para nada este punto fundamental; ni Bréal, que pensó que el -ndus pudiera ser el resultado de una disimilación del -menos en *-medos, luego -ndus; ni Thurneysen, que en un principio creyó ( $K Z$ 26, p. 303 ss.) que el -ndus pudiera proceder de un participio de presente facient- más un sufijo -no, de donde *facientnos $>$ faciendus. Aunque hay que reconocer que éste, en un acercamiento posterior al tema ( $K Z 30,1890-91$, p. 493), tuvo de él una visión enteramente distinta, y sin duda mucho más respetable. Pues entrevió que el -ndus pudiera ser una evolución fonética directa del -mnos. Una idea desde luego en oposición manifiesta con la teoría de las leyes fonéticas inexorables, pero que él apoyó en un 
hecho de indudable peso. $\mathrm{Y}$ es que en latín existió una partícula o un alargamiento $-n e$, atestiguado en postne/posne/pōne, que tras temas en $-m$ dio -mne >-nde. Así inde/exinde, unde/aliunde, salidos de ablativos en $-m$ (hinc, istinc, illinc, olim); y el umbro ponne/pone $<{ }^{*}$ quomne $=$ cum; y el quamde de los antiqui según Festo, en relación con magis < "quamne. Hechos todos perfectamente fundados, como indicaré a continuación, y que abren por lo tanto un interrogante del mayor interés, pero en los que Thurneysen no profundizó. Pues análogos a ellos se dan otra serie numerosa de casos, en los que Thurneysen no reparó. El único ejemplo que él quiso meter en la serie fue frendo, al que él consideró salido de *fremno, variante según él nasalizada de fremo. Hipótesis sin duda carente de toda base. Y claro está que con materiales $\tan$ escasos se comprende que no lograse hacer la menor impresión en la concepción general, fundada en la inexorabilidad de las leyes fonéticas, y en los numerosos casos con el -mnus.

Ahora bien, yo doy por descontado, como he indicado en numerosas ocasiones (cf. en especial Actas del 5. Congreso Español de Estudios Clásicos, Madrid 1978, pp. 29-131), que la teoría de la inexorabilidad de las leyes fonéticas, en la que por cierto se funda toda la Gramática Histórica, es un puro mito. Un mito que por lo demás ha sido la causa de la mayoría (de la infinidad pudiéramos decir) de las oscuridades que quedan en las Gramáticas de las lenguas ide. $Y$ ya he indicado también en múltiples ocasiones que la única condición para dar como válida una hipótesis en el terreno fonético es la que señaló Jespersen, Zur Lautgesetzfrage, en Linguistica-Selected Papers, 1933, pp. 160-205; es decir, el que el cambio supuesto en una forma esté atestiguado en circunstancias iguales en alguna o algunas otras formas. Para el caso importa poco el número de cambios que un sonido o un grupo de sonidos pudieron sufrir en el curso del tiempo dentro de la misma lengua. La razón de estas anomalías es difícil determinarla con seguridad. Aunque en general parecen deberse a que al mismo sonido suelen tratarlo muchas veces las diversas capas sociales de manera algo diversa, a que dentro de toda lengua se suelen producir entrecruzamientos de la pronunciación culta con la de las clases más bajas e incultas. Lo que sin duda puede afirmarse es que ése es un fenómeno general en todas las lenguas, y que suele darse en combinaciones muy variadas. Por ejemplo, no tiene nada de extraño que alumnus, columna, calumnia, aerumna, omnis fuesen invasiones de la pronunciación vulgar en la culta, con el tiempo generalizadas, frente a las formas sin síncopa como femina, dominus, hominis, terminus, etc., propias de suyo de la lengua culta. Y por la misma razón no tiene nada de particular que paralelo al - $m n$-, 
de origen de suyo popular aunque generalizado en muchas palabras, en otras se desarrollase un $-n n$ - con asimilación de la $m$ anterior a la $n$ siguiente.

No sólo esto, sino que de hecho en latín hay un grupo de palabras, en el que el -mn- aparece convertido en -nn-. Así connascor, connecto, connexus, connitor, conniueo, connubium, etc., sin duda de *com-nascor, etcétera. Y desde luego hay que pensar que ese resultado no pudo ser una analogía de los numerosos casos, en los que el com- iba ante consonante dental o gutural y se hacía con- Pues tales casos estaban contrapesados por los no menos numerosos en que el com-iba ante labial o vocal y conservaba su $-m$. Hay pues que deducir que el $-m n$ - se hizo - nn-, porque entre los dos grupos había un gran parecido, y porque las capas populares tendieron a convertir el grupo - $m n$ - en -nn-. $\mathrm{Y}$ de hecho ya reconocen Stolz-Leumann, $H$. Gr.6, pp. 213-214 que en la lengua de la conversación el -mn- se hacía -nn-; así el alunnus, danno, Vertunno, colunna, etc. de las inscripciones. Y la prueba de lo generalizada que estuvo esta pronunciación en el latín popular nos la ofrecen las lenguas romances, que dan al -mn- el tratamiento de -nn-. Así el esp. daño, dueño, Coruña, escaño, sueño, etc., o ital. danno, donna, colonna, sonno, etcétera. Lo que pudiera objetarse es que el vulgarismo -nn- en vez de - $m n$ - remite a una época muy distante de la prehistoria en la que debería haber evolucionado el -mnos de los gerundivos. Pero ya indiqué en Actas del 5. Congreso Español de Estudios Clásicos que en general los vulgarismos de la época histórica no fueron más que continuación de hechos, que en la lengua vulgar tuvieron su origen desde la época más antigua. De hechos connaturales en la población del sustrato, pero que sólo en parte se impusieron en todas las capas sociales. $\mathrm{Y}$ en los casos como connascor, connitor, connubium, etc. vemos que efectivamente el -nn- <-mn- penetró en la lengua general. Luego se concibe perfectamente que de igual manera hubiese penetrado en las formas en -mnos de los gerundivos.

Por otra parte, a mí no me ofrece duda que, aparte de alumnus, hay en latín algunas otras palabras, que remiten a formaciones en -menos de características idénticas a los gerundivos y a los participios medios del griego. Así columna < columena, 'la que sobresale o se eleva', participio sobre la raíz ${ }^{*} k e l-/{ }^{*} \mathrm{kol}$ - atestiguada en lit. kelin, kelti 'se eleva' y en latín columen/culmen 'sostén' 7 ; y calumnia *calumnus *caluo


'cima' con un elemento nasal, y convertido en una forma geminada antecellere, excellere, praecellere, percellere, celsus, excelsus, etc. y en collis según creo de "colis. 
o *caluio 'criticar, calumniar, hacer imputaciones', atestiguado en el si caluitur de las XII tablas (cf. Ernout-Meillet y Walde-Hofmann); y Vertumnus 'dios de la vuelta del año (el invierno), y dios de los intercambios comerciales'; y a lo que creo aerumna 'pesadumbre, aflicción, pesar', que en el argot castrense adquirió el sentido de 'angarillas, aparejo de madera de doble horquilla', que se adaptaba a las bestias de carga y servía para llevar los bagajes y la impedimenta. Una palabra de la que me ocupé en otra ocasión (EMERITa 21, 1953, p. 177), y que, como allí indiqué, creo que debió proceder de un participio maereomenos, de maereor, -èris, èri 'estar apesadumbrado, estar agobiado o triste' (con pérdida disimilatoria de su $m$ inicial). La objeción principal que pudiera hacerse a esta hipótesis es que los verbos en -eo hicieron su gerundivo en -endus (monendus, tenendus, habendus, etc.). Pero éste entiendo que debió ser un resultado de la asimilación de los en -ēo, -ēs, -ēre a los en -o, -ās, -āre, según la analogía amas : amandus : monēs : monēndus. Algo así como creo que la sustitución del originario *legons, -ontis por legens, legentis no pudo ser más que una asimilación a lo en -ans, -antis, según la analogía *amasi, *amati : amans : *legesi, *legeti : legens (cf. mis Notas al Vocabulario jurídico latino, p. 34 ss.) y algo así como la sustitución de -undus primitivo por -endus en los verbos radicales no pudo ser más que una asimilación al -andus, según la analogía amans amandus: legens legendus. Es decir, yo no veo dificultad especial en que aerumna fuese la continuación de un *maere-o-mena o *maeromena, por influjo de los verbos radicales en -omenos y antes de que se generalizase el -eo:-endus. Y por supuesto lo que no ofrece la menor dificultad es que el -umnus de alumnus, columna, *legumnus, *amamnus, etc. evoluciona en *legunnus, *amannus, etc.

Con lo cual, como se ve, se explican con toda sencillez los gerundivos dialectales del tipo osco sakrannas 'sacrandae', úpsannam 'operandam', y umbro pihaner 'piandi', anferener 'circumferendi'. Formas que en general, como es sabido, se han considerado siempre que salieron de unas formas con -nd- como las latinas. Hipótesis ésta fundada en el hecho de que en umbro hay unas formas adverbiales con un alargamiento -ne, -no siempre detrás de $m$ : umbr. ponne < ${ }^{*} q u o m-n e$ 'cum', pane < *quam-ne 'quam', panupei < *quam-no-que 'quandoque', osco pun < *quon-ne, pan < *quan-ne, al parecer correspondientes a otras latinas con -de, -do: quande, quando, quandoque, quondam. Lo cual ha hecho pensar, dada la mayor frecuencia del alargamiento -de, -do en latín, que fue éste el origen del dialectal -ne, -no. Y en consecuencia ha llevado a creer que el - $n n$ - de los gerundivos dialectales procedió de las formas latinas con -nd. Pero ya veremos más adelante 
que esto no es más que un puro espejismo. Es decir, que la forma que tuvo el alargamiento no fue la de $-d e$, $-d o$, sino la de -ne, -no. Y en cualquier caso es claro que a partir de una forma con -nd- el problema de los gerundios y gerundivos se convierte en un enigma indescifrable. Mientras que en cambio el de las formas dialectales correspondientes se resuelve con toda sencillez a partir de los participios medios en -menos. Hay pues que deducir que debe estar aquí la solución de los gerundivos latinos, sin duda inseparables de los gerundivos dialectales.

Lo paradójico es que hasta ahora a nadie, fuera de a Thurneysen en el caso que he señalado, se le haya pasado por las mientes que en latín pudiese darse la evolución de -nn- a - nd-. Pues en realidad, aunque nadie lo haya advertido, éste fue en latín un fenómeno completamente corriente. Por lo menos a mí no me cabe duda que hay un grupo numeroso de formas latinas con -nd- procedente de -nn-. Así en primer lugar grundīre, atestiguado en los autores con una forma al lado grunnìre. Forma ésta sobre la que por cierto el App. Probi da una referencia equívoca, pues la desecha como incorrecta. Lo cual ha tenido una influencia perturbadora en el enjuiciamiento de ambas formas por los autores modernos. Pues éstos, inducidos por la creencia de que el gerundio-gerundivo tuvo originariamente una forma en -nd-, de la que habría salido el -nnus de los dialectos, han creído en general que lo correcto y originario fue grundīre, y que el grunnīre no fue más que una variante popular influida por el osco-umbro. Así en general todos los autores. Pero grunnìre con -nn-geminada fue una formación onomatopéyica evidente, que se explica por sí misma. Una formación como hinnīe 'relinchar', tinnīre 'tintinear' y gannire 'aullar, ladrar, gañir' (de donde esp. 'regañar'), garrīre 'parlotear', croccīre 'graznar', etc. Mientras que al supuesto grundire nadie ha podido encontrarle una etimología ni medianamente satisfactoria, ni aun admitiendo una supuesta raíz үрu-. No cabe pues duda que grunđīre no pudo salir más que de grunnīre. Lo que pudiera parecer sorprendente es que, siendo como digo el cambio $-n n->-n d$ - popular, en el pueblo tuviese menor arraigo que la forma con -nn-. Y de ahí el esp. gruñir y el fr. grogner $>$ *grunniare. Pero esto hay que atribuirlo, no a un influjo dialectal, ya que en los dialectos no hay ninguna prueba de que el -nd- evolucionase a -nn-, sino a que el pueblo conservó vivo el sentido de su carácter onomatopéyico, y mantuvo la -nn-, que era la expresión de ese carácter. Donde sin duda hay que ver un influjo dialectal es en las formas como Secunnus, Verecunnus, etc. de las inscripciones tardías y vulgares. Formas que a mi juicio deben representar, no precisamente el tratamiento fonético de 
$-n d$ - como -nn-, sino una asimilación del -ndus latino al gerundivo en -nnus de los dialectos.

Y lo mismo que de grundīre hay que decir de tendere 'extenderse o dirigirse hacia', con un valor evidentemente intensivo sobre todo en sus compuestos: contendo, extendo, intendo, ostendo. Verbos todos construidos sobre la raíz ten-, que dio en gr. $\tau \varepsilon(v \omega$ 'extender' y lat. tenēre. $\mathrm{Y}$ verbos que naturalmente contienen un alargamiento - do, cuya función y origen nadie ha podido explicar. Lo único que Ernout-Meillet, $D E L L$, indican, tanto en tendo como en los paralelos offen-do y defen-do, es que se trata de un sufijo de valor 'determinado'. Pero esto apenas es decir nada, puesto que Ernout-Meillet no indican de dónde procedó tal sufijo, ni de dónde le vino ese valor. Lo que parece claro, como digo, es el sentido intenso de tendo, tanto en sí mismo como sobre todo en sus compuestos. Lo cual explica que pudiese geminar su consonante interior. Y claro está que a partir de *tennere era natural que se produjese un tendere, como grundìre a partir de grunnìre. Lo curioso es que en latín quedaron huellas de que tendere en una época antigua tuvo una forma tennere. Así Pl., Mil. 1407: distennite y Donato tennitur frente a los codd. tenditur. Formas éstas, en particular el distennite, que según Sommer, $\mathrm{Hb}_{\cdot 3}$, p. 338 habrían sido dialectismos, tolerables en tiempos de Plauto por el numeroso público dialectal que llenaba la escena romana. Pero por mucho o poco extendida que hubiese estado en Roma la pronunciación dialectal en la época de Plauto, esa explicación es imposible, porque en los dialectos no hay la menor prueba de que a la -nd- la tratasen como -nn-. Ya que el único ejemplo en el que se cree se dio ese tratamiento, a saber los gerundivos, es falso. Hay pues que admitir que el distennite de Pl. y el tennitur de Donato prueban que en zonas populares la -nd- seguía pronunciándose todavía -nn-, algún tiempo después de generalizarse el -nnus >-ndus en los gerundivos.

$\mathrm{Y}$ por cierto, esta explicación de distennite hay que extenderla a mi juicio al dispennite del mismo verso de Pl., Mil. 1047 (en Nonio, frente al dispendite del $A$ y el distendite del $P$ ). Sin duda un imperativo de dispando o de su variante fonética dispendo 'extender, desplegar', y por lo mismo un derivado de pando. Verbo éste que a su vez no pudo proceder más que de un *patno, con la raíz de patēre y con el mismo elemento nasal que se ve en hom. $\pi i \tau v \eta \mu$, att. $\pi \varepsilon \tau \nless \alpha v v \nu \mu$. Esto lo reconocen todos los autores. Lo que plantea un problema oscuro es cómo de *patno podría haberse pasado al latín pando. Un problema que algunos han querido explicar ${ }^{8}$ por un fenómeno llamado de 'inter-

\footnotetext{
8 Asi Thurneysen, $K Z 16,1883-84$, p. 302; Planta, I, p. 281; y Sommer, $\mathrm{Hb}_{3}$, p. 235.
} 
vención' o de 'metátesis en contacto'; es decir, por el paso de $t n / d n$ a -nd-, que según se supone se habría dado ya en ide. en un par de palabras. A saber, en unda, lit. vanduõ < $u d n a$ 'agua', de donde hom. ¿ $\lambda \partial \varsigma \varsigma \delta v \eta$ 'ola del mar', ai. udán, udnás 'agua' y unatti, undati 'se extiende el agua'; y en fundus < *bhudhnos 'fondo, suelo', ai. budhnás, gr. $\pi \nu \theta \mu \eta v$ 'suelo, planta del pie'; y según algunos como Vendryes, MSL 18, 1912-14, p. 305, en mundus 'el universo', 'el globo terráqueo', 'la bóveda del cielo', 'el mundo subterráneo', a mi entender de origen oscuro. Pero esta interpretación hay que considerarla inválida, puesto que el -tn- de *patno se conservó todavía en osco patensins < *patensens $=$ panderent, aperirent, $\mathrm{y}$ por tanto también en latín. $\mathrm{Y}$ en latín no se conoce ningún ejemplo de tal 'intervención'. Hipótesis admitida por algunos otros autores, pero sobre etimologías en absoluto insostenibles ${ }^{9}$. Es decir, que * patno en latín no pudo dar más resultado que padno $>$ * panno. Cosa que en general admiten todos los autores. $\mathbf{Y}$ de ahí que Godel, Cahiers de Saussure 18, p. 81 propusiese explicar el *panno > pando por un influjo de scando. Hipótesis a todas luces carente de verosimilitud. Lo que como vemos se explica con toda sencillez es el cambio -nn-> -nd-. Y como digo, el dispennite en vez de dispendite está atestiguado en Plauto, al lado de distennite en vez de distendite. Luego todo indica que ambos procedieron de formas con -nn-; y que además el cambio -nn-> -nd- no estaba consumado del todo en tiempos de Plauto, al menos en las formas que no eran gerundivos.

$\mathrm{Y}$ lo mismo que a tendere hay que interpretar a frendere. Un verbo que nos ha llegado transmitido con dos acepciones desconcertantes y no fáciles de conciliar. Pues al lado del sentido más general y corriente de «rechinar los dientes» como expresión de ira, hay una larga tradición gramatical, confirmada por una serie de textos vivos, que le atribuye el sentido de atriturar, moler». Una tradición además de larga muy antigua, pues aparece atestiguada ya en Varr., $R$. $r$. II 4, 17: cum porci depulsi sunt a mamma ... amisso nomine lactentes dicuntur nefrendes, $a b$ eo quod nondum fabam frendere possunt, id est frangere. Que fue sin duda la fuente de donde la noticia pasó a los gramáticos posteriores: Escauro, Gramm. Lat. VII 12, 4; Serv., Aen. VIII 230; P. F., p. 81, 8 y 157, 9; Isid., Orig., etc.; y de ellos a los autores literarios:

9 Por ejemplo por Sturtevant, Language 20, 1944, pp. 206-211, quien quiso explicar el gerundivo -ndus como un alargamiento de un tema en -nd-<-tn-, salido, según él, de nombres verbales como los hititas en -atar, genit. annas <-atnas. Pero en latín el único ejemplo de este tipo es iter, itineris, sin duda formación secundaria sobre *itinis, y que muestra en el gerundivo : gerundio otro grado vocálico: eundi, scribundi, legundi, etc. Y lo mismo puede decirse de los casos análogos con paso de $t n->\cdot n d$ - supuestos por Szemerényi, Transact. Phil. Soc., 1950, pp. 169-179. 
Celso, Columela, Plinio, Marcial, Paladio, Vegecio, etc. Lo cual parece no dejar lugar a la menor duda sobre la existencia y la antigüedad de este sentido. Y en esta opinión se funda la etimología generalmente aceptada de la palabra por los autores modernos, quienes suponen que frendo procedió de *ghren-dho, relacionado con anglos. grindan, lit. gréndu 'frotar, frotar fuertemente'; de donde según se dice tenere, contenere, y luego rechinar los dientes en señal de ira ${ }^{10}$.

Pero el hecho es que frendere 'rechinar los dientes' aparece documentada ya en P1., Truc. 601, antes que cualquier testimonio con el sentido de «moler». Y además ocurre (¡detalle curiosísimo!) que el sentido de "moler» aparece referido siempre en los autores latinos a las habas, como indicó ya Varrón. Hay sin duda dos o tres pasajes, en que en vez de a las habas aparece referido a früges. Pero de esos pasajes uno (Acc., Trag. 478: saxo fruges frendas torridas) es sumamente dudoso; pues en vez del frendas de Nonio, p. 717, autor muy descuidado, Serv. ad Aen. I 179 da la lectura franges. Y naturalmente, asegurado por la tradición gramatical el frendere «moler las habas», no tendría nada de particular que o Nonio o alguno de sus copistas lo refieriese a früges; por ej. Pacuv., Trag. 11: fruges frendo, transmitido también por Nonio, loc. cit. ${ }^{11}$. En todo caso es evidente que para los latinos frendere "moler» llevó adherida precisamente la idea de 'moler habas'. Y claro está que este hecho plantea dos proble. mas de no fácil solución. Uno, el que es difícil concebir por qué la idea de 'moler' se habría especificado en el sentido exclusivo de 'moler habas'. Y otro, aún más difícil, el de cómo del sentido de 'moler habas' se habría pasado al de 'rechinar los dientes en señal de ira', que fue su sentido con mucho más general. Indudablemente todo lleva a pensar que aquí se oculta algún fenómeno misterioso. Y esta impresión se refuerza por otra nueva circunstancia. Y es que, descartado el fruges frendas atribuido por Nonio a Accio, no quedan del frendere fabam y de faba fresa más que dos testimonios anteriores a Varrón. A saber, por una parte Cat., Agr. 90, donde a propósito de que a los palomos se les engorda de pequeños introduciéndoles en la boca fabam coctam «habas cocidas", añade: postea fabam fresam puram et far purum facito. Pero resulta que el ms. A da sólo fabam sin fresam. Todo indica pues que el fresam debe ser una glosa, sugerida por la idea de que a

10 Aunque no deja de ser significativo que Stolz-Leumann, H. Gr.6, no toman en cuenta la palabra, es de suponer que por no considerar segura esa etimología; y que Sommer, $\mathrm{Hb}_{3}$, p. 186 solamente la da como probable.

11 Por cierto que Nonio da de frendere la definición exacta y correcta: fremere et frendere hoc disparantur, quod est fremere magnum sonare. $\mathbf{Y}$ naturalmente bajo este lema es una incongruencia incluir los ejemplos con fruges frendere. 
las habas había que cortarlas en pedazos, para dárselas a los palominos pequeños. Una glosa probablemente introducida en el texto en el curso de la transmisión, por influjo de la tradición gramatical. Y lo mismo hay que pensar del fruges frendo de Pacuv. Trag. 11. Todo pues induce a pensar que el frendere fabam y el faba fresa procedieron del pasaje ya citado de Varrón, aceptado como muchas de las ideas de Varrón como un dogma por los gramáticos posteriores, y en consecuencia por los autores literarios.

Lo cual quiere decir que, aunque apoyado en una tradición al parecer imponente, la noticia del frendere = frangere o terere, descansa en un testimonio único. $\mathrm{Y}$ además en un testimonio que antes de Varrón no parece refrendado por ningún texto vivo. Pues la noticia la da Varrón sólo y exclusivamente para aclarar una etimología. Una etimología por lo demás sin duda falsa. Pues morfológicamente es imposible, a pesar de Ernout-Meillet, DELL, un *nefrens, nefrendis. $\mathrm{Y}$ de hecho ni Stolz-Leumann, $H$. Gr.6, pp. 161 y 169 , ni Walde-Hofmann, $W b_{\cdot 3}$, aun considerando a nefrendes un compuesto de ne y frendo, pueden explicar cómo podría haberse llegado a esa forma. Ahora bien, a mí no me extraña que Varrón, dados los conocimientos lingüísticos de su época, viese en nefrendes un derivado de frendere. Como me parece natural que viese una cierta relación entre los sentidos tan diferentes de 'rechinar los dientes' y de 'moler' (sc. dentibus). Y de ahí su etimología. Lo que no comprendo es que del sentido de 'moler las habas' en particular se hubiese pasado al de 'rechinar los dientes'. Como a su vez tampoco comprendo que del de 'rechinar los dientes' se hubiese verificado el paso inverso. Y puesto que el sentido de 'moler las habas' no está atestiguado más que en autores posteriores a Varrón, deduzco que esa acepción no fue más que una invención de Varrón, sugerida por una etimología popular. Es decir, que en su origen frendere 'moler' no fue más que una forma fantasma, consagrada como doctrina gramatical por la autoridad de Varrón y aceptada luego por algunos autores literarios. $\mathrm{O}$ lo que es lo mismo, que en latín no hubo más forma auténtica y procedente del ide. que frendere 'rechinar los dientes' (o como dice Nonio magnum sonare o magnum fremere).

Ahora bien, es claro que ese sentido de frendere se confundía con el de fremere 'rugir, bramar, hacer un ruido sordo' como muestra de

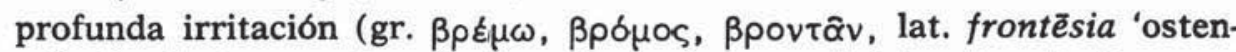
$\left.\mathrm{ta}^{\prime}\right)$. Es decir, que frendere no fue más que el intensivo de fremere. No tiene pues nada de extraño que sobre fremere se desarrollase un ${ }^{\star}$ fremmere con geminación intensiva. Desde luego que - $m m$ - no tenía por qué dar el mismo resultado que -nn-. Pero no hay que olvidar que 
*fremmere llevaba en inicial el grupo $f r$ - con una labial. No tiene pues nada de extraño que por una disimilación *fremmere se convirtiese en *frennere, luego frendere, probablemente a través de un grado intermedio *fremnere.

Y lo mismo que de los anteriores hay que decir de prendere, prehendere, praehendere. Formas que hoy los autores suelen dar como relacionadas con gr., $\chi \propto \nu \delta \delta v \omega$, sobre una supuesta raíz *ghed-, que suponen atestiguada por praeda 'botín' y hedera 'yedra'. Y formas entre las que se suele suponer un desarrollo inverso al aquí propuesto. Pues se suele partir de que la forma originaria fue *prai-hendo/prae-hendo, que ya en la época prehistórica habría cambiado su ae por $\bar{e}$ en la lengua popular, de donde prehendo y el prendo de los mss. de Plauto. Pero del simple *hendo en latín no quedó la menor huella. Y el sentido de 'contener' yo no creo que tenga la menor relación con el de prendo, prehendo, praehendo 'aprehender, apresar, asir'. Y por lo demás es una hipótesis gratuita la de que praeda y hedera tuviesen el origen *ghed- que se las atribuye. Y por otra parte no se comprende lo que prai- pudo añadir al sentido de *ghed-, ni por qué en latín el verbo se habría constituido sobre el grado *ghend- del futuro griego $\chi \varepsilon l \sigma o \mu \propto \iota$. Lo que no admite duda es que en la lengua popular fue corriente desde la época prehistórica la confusión de $a e$ con $\bar{e}$. Pero lo que no se comprende es la $e$ del prehendo de los mss. de Plauto. Como tampoco se comprende que si en época de Plauto se generalizaron ya las formas prendo y prehendo, resurgiesen posteriormente las con prae. Aparte de que, dado lo extendidos que estuvieron los compuestos con prae-, se hace difícil comprender que a un *prai-hendo se impusiesen ya en época plautina las formas como prendo y prehendo. Indudablemente a $\mathrm{mi}$ lo que me indican estos hechos es que la forma no fue un compuesto, ni de la raíz *ghed-, ni de ninguna otra, sino que debió surgir con la forma prendere.

Por lo demás, a mí me parece que prendere y sus diversas variantes tuvieron un sentido intensivo 'coger o asir fuertemente, tener fuerte. mente asido'. Un sentido que no es más que una modalidad del de premere 'oprimir, apretar, estrechar'. No tiene pues nada de extraño que pudiese proceder de *premmere, surgido sobre premere con la geminación característica de las expresiones intensivas. De un ${ }^{*}$ premmere, que pudo pasar a *premnere $>$ prennere $>$ luego prendere, por la misma razón que *fremmere pasó a frendere. $\mathrm{Y}$ naturalmente que, dado su carácter intensivo, no tiene nada de extraño que, además de geminar su consonante, alargase su $e$ radical, y se convirtiese en * prēnnere $>$ ${ }^{*}$ preendere, y con $h$ antihiática prehendere (cf. uehemens $<u e \overline{m e n s}$, 
y ahēnus < *aiesnos, etc.) ${ }^{12}$. El que prehendere se convirtiese finalmente en prehendere no fue más que un contagio con el grupo numeroso de verbos comenzando con prae- Todo indica pues que el desarrollo de la palabra siguió un camino inverso al que se suele suponer.

$\mathrm{Y}$ en este grupo hay que incluir a lo que creo a of-fendere y defendere. Grupo sin duda salido, como suele admitirse, de una raíz * $g^{\sharp}$ hen 'golpear, chocar fuertemente', de donde gr. $\theta \varepsilon l v \omega$, ai. han-, hit. kuenzi, y el intensivo latino infensus $<$ in $+{ }^{*}$ fensus. Pero los verbos latinos tienen un elemento -do, del que no ha podido decirse nada en concreto, añadido a la raíz. Ahora bien, la raíz entrañaba sin duda un sentido intensivo, subrayado en el adjetivo infensus. No tiene pues nada de extraño que en latín hubiese geminado su consonante, y se hubiese convertido en *fennere, de donde -fendere.

Y como otro caso análogo a los anteriores hay que considerar a mi juicio a otro verbo también intensivo candère 'tener un color blanco brillante' (cf. candidus). Verbo al que los autores modernos suelen dar por un derivado de un tema cand-, atestiguado según se dice en gr.

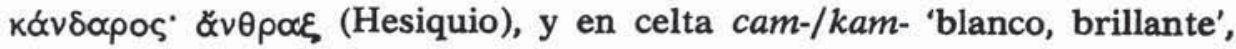
y en ai. cand- 'brillante', candrás 'luminoso'. Pero la relación del sentido de $\measuredangle \dot{ } \alpha \theta \rho \propto \xi \xi$ 'carbón' con el de 'blanco, brillante' me parece difícil que pueda darse como segura. $\mathrm{Y}$ el celta cam-/ kam- no parece que pruebe gran cosa, puesto que le falta el elemento - $d$ (dado que los topónimos como Cantobennicus son siempre formas sumamente ambiguas y dudosas). $\mathrm{Y}$ por otra parte las formas latinas con cand- representan

12 El que la intensidad semántica produjese alargamientos vocálicos es cosa hasta ahora no advertida por los autores. Pero en latín hay una serie de palabras hasta ahora inexplicables, y que se explican sencillamente como resultados de unos alargamientos vocálicos expresivos. Así tōtus < tot, cf. mis Estudios de Fonética, pp. 57 y 60; y así el causativo sópio < *sopeo, con -io en vez de -eo por influjo de dormio; y así mōles frente a molestus, y ācer frente a acus, acies, acuo. Grupos éstos en los que según Stolz-Leumann, $\boldsymbol{H}$. Gr.6, p. 100 las formas con breve pudieran ser a la inversa el resultado de un abreviamiento de las con $\bar{a}$ y $\delta$ (móles, äcer) en posición pretónica. Pero en latín no se conocen ejemplos de que las vocales largas pretónicas se abreviasen. Y si la $\bar{a}$ de äcer hubiera sido por naturaleza larga, ¿cómo explicar el acus, acies, acuo, y en posición tónica? $\mathbf{Y}$ así en fin a mi juicio sōlus 'solo, solitario, aislado de otros seres'. Forma ésta sobre la que se han propuesto las hipótesis más inverosímiles (cf. Ernout-Meillet y WaldeHofmann), y que sin duda no fue más que una variante intensiva de *solos

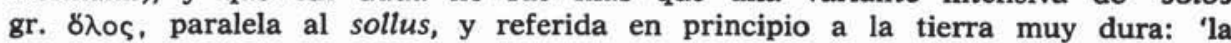
tierra-sólo-tierra, la tierra desprovista de vegetación y de vivientes, los desiertos o sōlitūdines'. Que fue el sentido más frecuente en que Plauto la usó. Por cierto que en totus 'todo' existió al lado una variante tottus, reprendida por Consencio V 392, 1, pero atestiguada en fr. tout, ital. tutto, que presenta como "prendere $>$ *preendere $>$ prehendere el doble fenómeno de la geminación consonántica y del alargamiento vocálico.

$\mathrm{XLIX}, 2 .^{\circ}-5$ 
un grupo muy cerrado y típicamente latino (candeo, candor, candidus), sin relación por su estructura con las del grupo del ai. Con el que se ve que candēre tiene una relación íntima es con cānēre cānus del que candēre y ac-cendere parecen intensivos. $\mathrm{Y}$ ya vemos que en latín la geminación expresiva fue un procedimiento muy usual para expresar la intensidad. Yo me inclino pues a creer que candēre debió ser un resultado de *cannēre < cānēre, con evolución de su -nn- a -nd-13.

$\mathbf{Y}$ otro caso análogo a los anteriores es el de splendēre, con un sentido intensivo evidente de 'brillar, tener un color blanco brillante'. Sen-

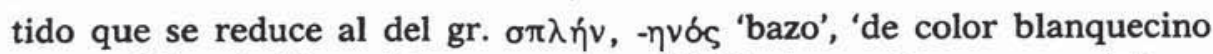
como el bazo'. El problema que esta hipótesis suscita es que al bazo se le llamó en latín liēn, con el mismo tema que el ai. ptīhán y que sin duda en su origen debió tener una forma con *spl- inicial. Pues en ide. son frecuentes los grupos iniciales de ese tipo con o $\sin s$ inicial (la llamada $s$ mobile). Pero con independencia de esto es claro que la diferencia de las formas latina e india respecto a la griega plantea una serie de problemas difíciles de resolver. Por ejemplo, el de si las distintas palabras pertenecieron o no al mismo tema, y el de cómo pudieron formarse las diversas variantes, y el de cómo pudo perderse en el lat. lien la $p$ - de *plian o *plighen, y sobre todo cómo en latín pudo surgir un splendēre, faltando el tema base *splēn. Pero en principio yo no veo ninguna dificultad especial en que del mismo tema hubiese en ide. dos variantes: *splēn y *splian. Que existiesen en ide., y que pudiesen seguir existiendo hasta una época más o menos tardía en las lenguas históricas. $Y$ en todo caso me parece imposible que, dado su sentido, splendēre pueda separarse de $\sigma \pi \lambda \eta \dot{v}$ y del lit. bluznis 'brillo'. Por lo tanto me inclino a creer que splendēre debió ser el resultado de *splennēre, salido de una forma como gr. $\sigma \pi \lambda \eta \eta v$ con geminación intensiva de su $-n$.

$\mathrm{Y}$ esta lista pudiera alargarse con otra serie de casos análogos con temas nominales. Por ej., grando, -inis 'granizo'. Voz sobre la que no ha podido presentarse ninguna hipótesis satisfactoria, y que ni Sommer ni Stolz-Leumann toman en cuenta, sin duda por considerarla de origen oscuro. Pero claro está que el sentido de grando se identifica con el de grānum. Ya que el granizo está formado por granos, de ordinario más abultados que los granos en general. Es decir, que semánticamente el

13 El problema de esta hipótesis es que a cānus se le suele derivar del tema "casnos, pelign. casnar 'viejo' (con la misma raí cas- de cascus). Pero a mí me parece muy dudoso que una palabra tan rara como pelign. casnar pudiese ser el origen de cănus. 
granizo es también por esencia un intensivo. Y morfológicamente la única diferencia entre grānum y grando es que éste contiene el sufijo $-\bar{n} n$, ōnis o -inis. Pero en latín fueron normales los derivados en -on, -inis sobre temas en -o y en -a. Así homo, -inis sobre la raíz de humus, y probablemente uirgo, -inis sobre uirga 'renuevo o vástago joven' (cf.


ción prenest. nefrones y lanuv. nebrundines 'riñones' y 'testículos' sobre la raíz *negk'rós, gr. $v \varepsilon \phi \rho o l$ 'riñones'. No tiene pues nada de particular que sobre un *grannum, intensivo de grānum, se formase un *granno, -inis $>$ grando, -inis.

$\mathrm{Y}$ así también grandis, -e 'grande, de gran tamaño, importante', etc. Voz que alguno quiso derivar (Wiedemann, $B B$ 13, p. 310) de la raíz gurendh-, atestiguada según se dice en gr. $\beta p \varepsilon v \theta 0 \dot{0} \mu \alpha \mathrm{t}$ 'ser orgulloso', 'hincharse, hacerse el valiente', $\beta \rho \varepsilon v \forall$ os 'orgullo', irl. ant. bruinne 'pecho'. Pero la relación semántica de grandis con las formas griegas, por lo demás de origen oscuro, es muy remota. Y la relación con el irl. ant. bruinne la rechazan Walde-Hofmann. Y de ahí que Ernout-Meillet reconocen que la palabra no tiene etimología segura. Frente a esto, a mí me parece que semánticamente grandis remite a una forma de sentido intenso. Un sentido que de suyo parece adaptarse mal al de gränum 'grano, pequeño abultamiento'. Pero ya he indicado que grānum admitió un sentido aumentativo de 'muy grueso, muy abultado' supuesto por grando, -inis de *granno, -inis < *grānnum < grānum. Yo no veo pues ningún inconveniente en que grandis pudiera ser una variante del mismo * grannum. El problema es que el tema sustantivo de grānum se presenta en grandis bajo la forma de un adjetivo en -is. Pero en los adjetivos fue en latín corriente que los temas en -os se transformasen en temas en -is: forctis y fortis de forctus, fortus, lēuis 'liso' gr. $\lambda \varepsilon i \hat{F}$ os, similis gr. $\delta \mu \propto \lambda \delta \varsigma$, humilis gr. $\chi \theta \propto \mu \alpha \lambda \delta \delta$, sustant. ceiuis, ai. sivas 'amistoso'. No veo pues ningún inconveniente en que grandis pudiese ser una variante de grānum/*grannum, que originariamente debió ser un adjetivo en -nus, como plē-nus, uānus, dō-num, mag-nus, etc., y que fue de una forma adjetiva *grannus de donde salió el *grannis $>$ grandis.

$\mathrm{Y}$ así glans, glandis 'bellota', sin duda de la misma raíz *gelon del gr. $\beta \dot{\alpha} \lambda \lambda \propto v o \varsigma$, de cuya $d$ tampoco ha podido darse razón. Pero yo entiendo que esa $d$ admite una explicación sencilla a partir de una geminación de la $n$ en los casos oblicuos; es decir, a partir de *glannis, *glanni, etc., de donde glandis, glandi, etc. Por cierto que en Avieno glans aparece sustituida por glando, -inis. Pero esto no fue más que una consecuencia de que, sintiéndose una gran diferencia entre glans y glandis, se rehizo por asimilación a los oblicuos un nominativo 
glando, sobre el que se recreó un nuevo paradigma por analogía a los en -o, -inis: homo, -inis, uirgo, -inis, turbo, -inis, ordo, -inis, etc. ${ }^{14}$.

$\mathrm{Y}$ así el lanuv. nebrundines 'riñones' y 'testículos', y el nefrundines de los antiqui según P. F. 344, con los que P. F. 157, sin duda por confusión relacionó el nefrendes 'lactentes'. Formas sin duda fundadas en un alargamiento en -on, -onos, atestiguado en prenest. nefrones,

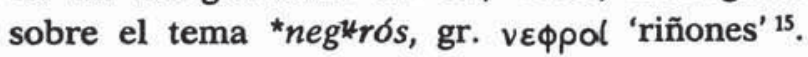

En un alargamiento como los recién citados (homo, uirgo, turbo, etcétera), que en los oblicuos unas veces conservó la vocal breve apofónica anterior al sufijo (hominis, uirginis), y otras generalizó la vocal larga del nominativo: lat. hemōnem, osco humuns 'homines', umbro homonus 'hominibus'. Esto parece que no ofrece dudas. De lo que nadie ha podido dar razón dentro de las ideas corrientes sobre las leyes fonéticas es del desarrollo del -on en -undo, -undinis. Pero sobre esto creo que da una luz preciosa un hecho del español. Y es que en español palabras como riñones, reaños, y sobre todo como cojones o testículos (forma ésta eminentemente popular) se suelen pronunciar en el pueblo con un énfasis y una fuerza especial. El pueblo nunca pronuncia 'cojones' como brazo, pie, pierna, pecho o cualquiera otra de las partes del cuerpo. Esto salta a la vista de cualquiera que haya observado la lengua del pueblo. No tiene pues nada de particular que por un fenómeno idéntico los latinos en los casos oblicuos reforzasen la $n$ de nefrones / *nebrones, y convirtiesen a estas formas en *nefronnes / "nebronnes, que naturalmente debieron convertirse en *nefrondes /*nebrondes. Ahora bien, no cabe duda que un paradigma como ése creaba una gran diferencia entre el nominativo *nefro / *nebro y los demás casos. Y por otra parte es claro que la palabra debió sin duda usarse sobre todo en plural, lo mismo exactamente que el gr. $v \varepsilon \phi p o l$. No tiene pues nada de particular que por analogía de los casos oblicuos, sobre todo del plural, se crease un nominativo sing. nebrundo; y que luego sobre esto se rehiciese un paradigma general nebrundo, -inis, por analogía de los temas como homo, uirgo, turbo, -inis, etc. El caso es exactamente igual al de glando, -inis de Avieno frente a glans, glandis.

14 Un problema misterioso es que en algunas lenguas la raíz aparece como en latín con un alargamiento $-d$-: ruso ant. zeludo, alb. lend. Pero esto pudiera ser un resultado de que la palabra se formó en las distintas lenguas con un sufijo distinto sobre una base primaria "gela.

15 Por cierto que el hemōnem yo no creo que suponga en latín la alternancia "ghem-, frente a homo y humus, osco humuns, umbro homonus = homines, sino que sencillamente fue un regresivo de nẻmo, forma a su vez salida de *ne-homo; cf. Estudios de Fonética, p. 259. Eso en el caso de que hemonem no sea una falsa grafia de homonem. 
$\mathrm{Y}$ al lado de nebrundines / nefrundines hay que colocar el nefrendes, citado por Varrón y otros gramáticos, y documentado en Festo, 156 por un pasaje de Liv. Andr., Trag. 38: Quem ego nefrendem alui lacteam immulgens opem. Una palabra que, como he dicho, morfológicamente es imposible que procediese de ne más frendere, como propuso Varrón y al parecer han creído aunque con dudas algunos autores. Y no sólo morfológicamente, sino que también en el terreno semántico tropieza tal hipótesis con una dificultad insalvable. Pues sin duda nefrendes significó en general toda clase de lactentes, lechones o crías pequeñas todavía en estado de lactancia: los porci de Varrón, los arietes de P. F., los infantes de Ateyo Capitón, etc. Y claro está que a los niños no pudo llamárseles lactentes, porque no pudiesen 'triturar las habas', que fue lo que según los antiguos significó por esencia frendere. Lo curioso frente a esto es que en griego existió una palabra $v \varepsilon \beta \rho \delta \delta_{\varsigma}$ 'cervatillo', atestiguada ya en la Iliada. Una palabra procedente sin duda de *negł rós, y que sin duda significó 'toda clase de animales pequeños' apenas salidos de la lactancia. Y por supuesto no tiene nada de particular que de un tema como ése se sacase en derivado *negurōn, -ōnes o -ēnes (análogo al homo, uirgo, turbo, -inis, etc.). Como no tiene nada de particular que *neg"ren-es por una geminación expresiva se convirtiese en *negkrennes, que naturalmente en latín se comprende pudiese convertirse en $-n d$. Es decir, que morfológica y semánticamente se comprende perfectamente que en latín un *neguron, *neg ${ }^{\sharp}$ ren-es / *negkrennes pudiese haber dado un *nebrendes, idéntico por su sentido a nefrendes.

Lo inconcebible es que en latín un grupo $-g^{u} r$ - pudiese haber dado un resultado - $f r$. Y no sólo en latín, sino que incluso en los dialectos es a su vez a primera vista imposible un cambio como el de $-g^{\mathbb{k}} r$ - con simple oclusiva sonora en - $f r$ - Que ha sido sin duda la causa principal de que nadie haya pensado en esta solución. Pero respecto a los dialectos hay que hacer una observación hasta ahora no advertida. Y es que la lengua del sustrato preide. en Italia o al menos en la mayor parte de Italia fue el etrusco ${ }^{16}$. Y el etrusco no poseyó (cf. Pfiffig, Die Etr. Sprache, p. $38 \mathrm{ss}$.) lo mismo que la población del sustrato preide. del griego, el pelasgo (cf. Heubeck, Praegraeca, p. 23), más que dos series de oclusivas: las oclusivas sordas y las aspiradas (tratadas en Italia muchas veces como espirantes). Por ejemplo, en etrusco en concreto ocurre que a las oclusivas sonoras, que ellos recibieron en los préstamos del griego, las transformaron en fonemas con igual punto

16 Cf. Actas del 5.o Congreso Español de Estudios Clásicos, p. 125. 
de articulación que los que ellos poseían; a saber, en oclusivas sordas o en aspiradas o espirantes, de esto hay en etrusco innumerables ejemplos, cf. Devoto, "Tendenze fonetiche etrusche», Studi etruschi 1, 1927, p. 255 ss. Ahora bien, los dialectos itálicos fueron lenguas ide.; lenguas que poseyeron y conservaron muchas veces las oclusivas sonoras. Pero no es menos cierto que, como lenguas literariamente mucho menos cultivadas que el latín, debieron estar, al menos en las capas inferiores, muchísimo más sometidas que el latín a los influjos del sustrato; sobre todo a los influjos fonéticos particularmente fáciles de transmitir entre lenguas con sistemas fonéticos distintos. No tiene pues nada de particular que en la reproducción de las oclusivas sonoras se verificasen transmutaciones parecidas a las del etrusco; y que por ejemplo a las sonoras se las convirtiese en espirantes ${ }^{17}$. $Y$ de hecho hay palabras en otro caso difíciles de explicar y que se explican perfectamente mediante tal transformación.

Así por ej. umbro prufe 'probē', o amprufid 'improbē' y prufattens 'probauerunt', que se suelen por esto derivar de un ide. * probhus, supuesto compuesto con -bhu-, de donde lat. probus. Pero ya indiqué en otra ocasión (EMRRITA 38, 1970, p. 216) que ni en ide. existieron ese tipo de compuestos, ni en latín se concibe el paso del tema en $u$ a tema en $o$, ni la existencia de temas adjetivos en $u$. Como en latín se explica sencillamente esa palabra es como una alteración de *prouos en probus para diferenciarla de prāuos. Alteración de la que son otros ejemplos

17 Sobre los influjos del sustrato en lenguas anteriores desplazadas por otras con sistema fonético distinto, como fue el caso de las lenguas itálicas suplantadas por el ide., tuvo observaciones muy agudas el jesuita español Hervás y Panduro, el predecesor en cierto modo de Ascoli en su teoría del sustrato, como ha indicado recientemente Coseriu en Studii si cercetari linguistice 29, 1978, p. 528 ss. Observaciones en las que los Neogramáticos apenas han reparado, obsesionados por el principio de las leyes fonéticas (que evidentemente no son más que un prejuicio), pero que tienen una validez general. Pues no hay que olvidar que todas las lenguas ide. se desarrollaron no en el vacío, es decir en territorios carentes de población, sino que se impusieron a pueblos que poseían ya unas lenguas con un léxico distinto y con unos sistemas fonéticos distintos del ide. Lo cual produjo una serie importantísima de hechos léxicos y fonéticos en las lenguas importadas. Recuérdese que gran parte de los nombres personales itálicos se formaron sobre topónimos de origen preide., frente a lo que en general pensó Schulze (Gesch. d. lat. Eigenn.) y de acuerdo con él han venido creyendo la mayoría de los autores desde 1904, para quienes los topónimos habrían salido de nombres personales. Y recuérdese que la mayoría de los topónimos de la América Hispana y Portuguesa están formados sobre temas americanos. Y lo mismo puede decirse de muchos cambios, tanto en latín como en los dialectos itálicos, que se debieron no sólo a las consideradas leyes fonéticas, sino a desajustes entre el sistema fonético ide. y el del sustrato. Pues el influjo del sustrato es un hecho para mí indiscutible, a pesar de las objeciones que esa teoria ha suscitado. Sobre esto pienso ocuparme con mayor extensión en algún otro momento. 
acerbus frente a aceruus 'montón', superbus 'en punta' frente a *superuos (cf. propteruos), y uestigium 'huella o marca del pie', hoy dado como oscuro (Ernout-Meillet y Walde-Hofmann), sin duda de *bestigium < ${ }^{\star}$ ped-stīgium < stīgare. Hay pues que pensar que el umbro prufe, osco amprufid no fueron más que tratamientos dialectales de la misma forma que dio en latín probus.

$\mathrm{Y}$ así el osco 27, 1 y 27, 4 manafum, falsa grafía en vez de manafau= mando (cf. Homenaje a A. Tovar, Madrid 1972, p. 349). Forma semánticamente idéntica a mandāre (sin duda de *mano-dare) 'dar un poder, dar un encargo, confiar o entregar', y que no puede separarse morfológicamente de ésta. No puede separarse de ésta, porque en los dialectos itálicos no hay el menor vestigio de la raíz simple $d h \bar{e} /$ dha. Lo cual quita toda base al mandho, en el que algunos autores han pensado. Lo único que prueba es que la $d$ del mano-dare en osco a veces se transformó en - $f$. Para el caso importa poco que otras veces, incluso en do y sus compuestos (por ej. dede, didest, didet), y por supuesto en otras palabras, la $d$ se conservase. Pues este tipo de vacilaciones entre la pronunciación culta y la vulgar son corrientes en todas las lenguas.

$\mathrm{Y}$ así el falisco efilis, que sin duda tuvo que proceder de aedilis, $y$ al que hoy se le suele considerar como a éste continuación de un aidhilis, sobre una supuesta raíz *aidh-, de donde gr. $\alpha$ $\theta^{\dagger} \omega$ 'quemar'. Pero en primer lugar yo no creo que aedes, aedilis se formasen sobre la raíz de $\alpha \nmid \theta \omega$ como suele suponerse. No lo creo porque los únicos ejemplos de la raíz *aidh- que se citan en latín son aestus, aestiuus, aestas, y porque en latín en interior de palabra las aspiradas sonoras ide. ante consonante se convertían en oclusivas, que se asimilaban a consonante siguiente: scriptus < *scribhtos, iussus < *iudhtos, fisus < *bheidhtos, etc. Lo cual denota que aestus, aestas tuvieron que proceder de otra raíz distinta de *aidho. ¿No serían más bien estas formas una variante de *eustus, "eustas, salidas de *euso > üro, gr. $\varepsilon ̋ \omega$, ai. osāmi, con pérdida de su $u$ como en Augustus, esp. Agosto, ital. Aosta, y con confusión popular de $e$ con $a e$ ? ${ }^{18}$. Y en todo caso es obvio que los aediles, institución típica romana, no pudieron entrar en Falerii antes de principios del siglo IV, que fue cuando en Roma se crearon los aediles en relación con los tribunos de la plebe. Y en esa fecha hacía tiempo que las aspiradas sonoras ide. se habían convertido en latín en interior de palabra en oclusivas sonoras. No hay que olvidar que cuando Falerii fue

18 Sobre estas confusiones véase Actas del 5.0 Congr. Esp. de Est. Clásicos, p. 46 ss.; en cuanto al origen de aedes, aedilis pienso ocuparme en un artículo próximo. 
arrasada y sus habitantes obligados a abandonar su antiguo emplazamiento en las montañas fue el año 241 , como consecuencia de una sublevación imprevista el año final de la primera guerra púnica. Por lo tanto hay que deducir que la forma con que se introdujo en Falerii la palabra fue la de aedilis, y que la $-f$ - de efilis fue un tratamiento falisco o falisco-etrusco de la $d$ latina.

$\mathbf{Y}$ así igualmente el $a f$ en vez de $a b$, que aparece en las inscripciones latinas antes del imperio (af uobeis, af solo, af muro, af Capua, af louco, af speculo, etc.), y que todavía Cicerón encontró en el año 42 (Orat. 185) en las fórmulas mercantiles, y que en la época republicana debió tener mucha más vitalidad de lo que parece (cf. Havet, $A L L 9,1896$, p. 168). Una forma de la que no han podido proponerse más que hipótesis claramente insatisfactorias (por ej. Woelfflin, $A L L$ 7, 1892, p. 506 y Buecheler, Rhein. Mus. 46, 1891, p. 506), y que tanto Ernout-Meillet, $D E L L$ como Walde-Hofmann, $W b_{._{3}}$ dan por inexplicada. Lo único que insinúan Walde-Hofmann como Planta, II, p. 454 ss. y Ernout, Elem. dialect., p. 92 ss. es que debió ser un dialectismo. Cosa naturalmente imposible de admitir dentro del principio de las leyes fonéticas inexorables. Y de ahí las vacilaciones de estos autores. Pero cambios como ése (de sustitución de las oclusivas sonoras por espirantes) se dan como vemos en otras palabras de los dialectos. Hay pues que pensar que efectivamente esa $-f$ - no fue más que un tratamiento dialectal de la $b$ de $a b<$ apo, pasado al latín de la lengua popular o vulgar y en último término de los dialectos.

Y lo mismo que de éstas pudiera decirse de otras formas difíciles de explicar y desde luego hasta ahora inexplicadas; pero que admiten una explicación sencilla sobre los mismos supuestos que las anteriores. Es decir, a partir de que el paso a oclusivas sordas o a espirantes de las oclusivas ide. sonoras fue en ciertas capas de los dialectos un fenómeno bastante más corriente de lo que se supone. Un paso sin duda provocado por las diferencias entre el sistema fonético ide. y el de las lenguas del sustrato itálico. Para el caso importa poco que otras veces la sonora ide. (osco aidil, aidilis, etc.) se mantuviese. Por lo tanto no veo la menor dificultad en que el *-gk $r$ - de *negkren- / ${ }^{k} g^{k}$ renn- diese en los dialectos nefrendes en vez de *negrendes o *nebrendes. $\mathrm{Y}$ naturalmente que a través del latín rústico o vulgar no tiene nada de particular que la palabra penetrase en latín ${ }^{19}$.

19 Advierto que sobre la $f$ del prenestino nefrones y lat. nefrundines, y sobre otras palabras con -fr- interior de ide. -dh-, como inferus, infra, infimus, infula, existe una opinión muy extendida que no comparto. Pues como en latín las aspiradas sonoras ide. evolucionaron a oclusivas sonoras, se ha crefdo que la -f- pro- 
Un problema que surge espontáneamente ante estas conclusiones es: ¿y qué pensar de las otras dos palabras con final -undo, -undinis que quedan en latín: harundo / arundo 'caña' e hirundo, -inis 'golondrina', las dos dadas como de etimología desconocida? Ahora bien, sobre hirundo, palabra aislada y sin correspondencia en ninguna otra lengua ide., a mí ciertamente me es imposible formar juicio. Pero con harundo ( $s i n$ duda hipercaracterización en vez de arundo) sí que existió en griego una palabra al parecer emparentada, \&́pov 'caña'. Una palabra de origen desconocido (Pokorny en Idg. Wb. pregunta si no sería de origen mediterráneo), pero a la que tanto Pokorny como Frisk, Walde-Hofmann y Ernout-Meillet dan como posiblemente relacionada con arundo. Lo que ellos, incapaces de dar razón de nebrundines, se ven obligados a confesar es que no tiene explicación conocida. Pero claro está que a partir de un *aro 'caña', arundo se explica de igual manera que nebrundo, -inis. Es decir, a partir de un alargamiento en -on -onis o -enis con geminación expresiva de su $n$ : genit. *aronnis $>$ *arondis, de donde *arondo, "arondis, luego arundo, -inis. Por lo demás la identidad semántica entre ápov y arundo no puede ser más completa. Luego debemos deducir que arundo procedió de *aron, cualquiera que fuese su origen, y que constituye un caso del paso de - $n n$ a $-n d$ -

$\mathrm{Y}$ otro caso a lo que creo del mismo fenómeno es perendiē. Forma que se suele considerar como un compuesto de diē. Así Ernout-Meillet,

cedió de que los latinos vieron en el elemento inicial ne- e in- unas partículas y trataron a la aspirada siguiente como inicial de palabra y la convirtieron en $f$. Así ya Thurneysen, $K Z 30,1890$, p. 471 ; Sommer, $I F 11,1900$, p. 8 , y $H b$., p. 179 ; Walde-Hofmann, $W b_{.3}$, Stolz-Leumann, $H . G_{.6}$, pp. 166 y 169, etc. Frente a lo cual lo más que se les ha ocurrido pensar a algunos (Ernout, Elem. dial. lat., p. 184 ss., Meillet, Esq. hist. lat., p. 100, etc.) es que pudieron ser préstamos dialectales. Hipótesis inconcebible, dado que en los dialectos no existe la menor correspondencia de tales formas con $f$. Pero ya indiqué en emerita 11, 1943, p. 347 que los cambios fonéticos se producen automáticamente y con independencia de esta clase de consideraciones. Es decir, que la $f$ de tales palabras tuvo que estar determinada por las circunstancias fonéticas especiales que en ellas tuvieron que darse. Circunstancias que en infrā, inferus, infimus son fáciles de comprender. Pues tras la síncopa, que en la lengua popular debió ser natural: *ndherā $>$ *indhrā, *ndherus $>{ }^{*}$ indhros, ${ }^{*}$ ndhemos $>$ *indhmus, tuvieron que producirse unos grupos consonánticos complejos y difíciles de pronunciar. Lo cual hizo que la $d h$ quedase en posición equivalente a la $d h$ inicial de palabra y se convirtiese en $f$. Por lo demás advierto que para mí tanto infimus como inferus fueron el resultado de un cruce del vulgar *indhmus, *indhrus con el culto *indimus, ${ }^{*}$ indheros. Eso respecto a estas palabras. Pues en cuanto a infula sospecho que pudo ser un etrusquismo. $\mathrm{Y}$ en cuanto a nefrones y nefrundines es claro que la $f$ representa el tratamiento normal del $g^{u} h r$ en los dialectos. Hay pues que suponer que en estas palabras la $f$ se produjo de manera natural. Es decir que si en latín existió en alguna época nefrundines, y no fue una mala grafía de nebrundines, influida por nefrones y $v \varepsilon \phi \rho o l$, tuvo que ser por influjo dialectal en el bajo pueblo. 
y con más dudas Walde-Hofmann. Pero lo cierto es que sobre ese supuesto nadie ha podido dar razón del elemento inicial peren-. En cambio a mí me parece que el sentido de 'el día siguiente' al de manaña, 'pasado mañana', podía explicarse a partir de un adverbio perennē < perennis (cf. facile < facilis, propiamente 'todo el año', 'incesantemente'), de donde no era extraño que se desarrollase el de 'todo seguido', 'el otro día a continuación', 'pasado mañana'. La conversión de perennē en perendiē debió ser un fenómeno completamente natural, una vez que perennē se transformó fonéticamente en *perende ${ }^{20}$.

$Y$ dentro de esta hipótesis admiten una explicación sencilla una serie de formas adverbiales con un elemento alargante en -do, -de, -dam. Así en primer lugar las como nondum 'aún no', dūdum 'hace ya tiempo' necdum $=$ nondum, nullusdum 'ninguno hasta ahora', nihildum 'nada hasta ahora'. Formas de las que sin duda es imposible separar las expresiones en imperativo con-dum enclítica, como mane-dum, age-dum, circunspice-dum, ades-dum. Y con las que igualmente hay que relacionar el dum, originariamente adverbio 'mientras', luego conjunción temporal 'mientras que, entretanto que'. $\mathrm{Y}$ formas todas sobre las que hasta ahora no ha podido llegarse a ninguna conclusión segura, ni respecto a su origen ni respecto a su función primaria. Pues lo más que ha podido decirse es que dum debió ser un acusativo neutro, paralelo al cum, tum, de un tema pronominal *do, relacionado según se cree con dōnec, quando. Así el Thesaurus, aunque en éste se apuntan otras varias posibilidades; y por lo demás Ernout-Meillet, $D E L L$, y WaldeHofmann, $W b_{.3}$ y Schmalz-Hofmann-Szantyr, Lat. Synt., p. 609, etc. De un tema que se encontraría representado en aal. za, zuo, y en inglés to 'hacia', y en esl. ant. en la preposición do de genitivo, antes de ablativo. Es decir, de un tema que sería ide. Pero lo cierto es que ni de quando,, dōnec, ni de -dam (quondam, quidam), ni de -dum o dum hay correspondencias en ninguna otra lengua ide. $\mathrm{Y}$ en latín mismo no ha sido posible encontrar hasta ahora ninguna explicación satisfactoria de estas formas. Ya que en latín mismo, si se prescinde del oscuro donicum / donec, no quedaron indicios de un posible ${ }^{\star} d o,{ }^{\star} d a$ independiente más que en formas enclíticas. Así quandō, quōndam, e incluso como veremos el dum, originariamente un adverbio (nondum, dudum, mane-dum) convertido con el tiempo en conjunción temporal 'mientras que'. Y por otra parte se ve que no hay la más remota

20 Más aún, yo sospecho si el oscuro rotundus 'redondo', hasta ahora inexplicado, no serfa el resultado de un *rotunnus, forma intensiva de *rotūnus, un derivado éste de rota analógico de tribūnus $<$ tribus, lacuna $<$ lacus, Fortuna $<$ Fors, etc. 
posibilidad de relacionar el uso y sentido del *do ide. con el de las formas latinas con -do, -dam, -dum.

$\mathrm{Y}$, claro está, en estas circunstancias, y dada la inconsistencia de las etimologías propuestas, es difícil determinar la significación fundamental y el desarrollo de las funciones del $d u m^{21}$. Pero ya Loefstedt vio, Homenaje a Persson, Uppsala, p. 408, que el sentido originario de dum debió ser el de 'ahora'. Y a mi entender ese juicio se impone con la fuerza de lo evidente en las expresiones adverbiales, como nondum 'aún o todavía no', 'hasta ahora no', y nec-dum = nondum, y nullusdum 'ninguno hasta ahora', y nihildum 'nada hasta ahora', y dudum, sin duda de *diūdum (con disimilación de *iam diūdum; cf. eMERITA 44, 1976, p. 312 'hace ahora largo tiempo'). No sólo esto, sino que a mi juicio ese sentido de 'ahora' se compagina perfectamente con el uso enclítico del -dum con sentido intensivo tras imperativos y expresiones adverbiales. Pues, como es sabido, en la lengua hablada fue muy corriente el refuerzo de los imperativos y de los adverbios con partículas de la insistencia: age nunc, age ergo, dic ergo, aduorte quaeso, cura obsecro, etc. Partículas que corresponden exactamente a ejemplos como Pl., Bacch. 797: manedum parumper, o Ter., Andr. 29: ades-dum, paucis te uolo. Pues naturalmente el parumper y el paucis te uolo denotan que se trata de asuntos de un momento: 'quédate aquí ahora un momento', 'espérate un momento'. Y así el uixdum 'apenas, apenas inmediatamente, apenas justamente, apenas casi'. Cf. Ter., Phorm. 594: uixdum dimidium dixeram, intellexerat; Cic., Fam. XII 42: haec ego omnia uixdum etiam coetu nostro dimisso comperi; Liv., XXIX 42, 12: progressis uixdum quattuor milia passuum, etc. Es decir, que el -dum enclítico a mi juicio fue un simple desarrollo del -dum 'ahora', y no a la inversa, como indica Szantyr, Lat. Synt., p. 616. Más aún, ese valor de 'ahora' resalta claramente en casos de repetición del dum adverbio. Así por ej. Pl., Truc. 38: dum huc, dum illuc rete (circumu〉or〈tor), o como Merc. 348: dum perplacet mihi consilium, dum rursus hau placet 'unas veces me agrada mucho el plan, otras me desagrada'. Expresión por el sentido equivalente a 'ahora me agrada mucho, ahora no me agrada el plan'. Todo pues lleva a pensar con Loefstedt que el sentido originario de dum debió ser el de 'ahora'.

La única objeción que pudiera hacerse a esa hipótesis es que el valor fundamental de dum conjunción temporal, el de 'mientras que' o 'entretanto que', supone en el verbo correspondiente una acción dura-

${ }^{21}$ Esto lo reconoce expresamente Szantyr, loc. cit.: «Die Grundbedeutung laesst sich nicht zuletzt wegen der nicht eindeutig geklaert Etymologie, kaum mit Sicher. heit fixieren». 
tiva. Lo cual parece implicar una oposición con la idea puntual entrañada en la de 'ahora'. Aspecto que subrayó Brenner, Entwicklung der Funktionen der lat. Konj. dum, Zurich 1936. Pero ese sentido no fue más que una consecuencia del pequeño dislocamiento sintáctico que se produjo en el paso de la construcción paratáctica a la hipotáctica. Un paso que consistió sencillamente en que el dum enclítico se desligó del imperativo precedente, y se unió al verbo siguiente que quedó subordinado. Es decir, que de mane-dum, soluo, o de mane-dum, redeo, o de ades-dum, lego, se pasó a giros como mane, dum soluo, o mane, dum redeo, o ades, dum lego, etc. Un paso completamente natural, pues bastaba llevar la pequeña pausa de detrás del dum a antes de éste, a continuación del imperativo, para que surgiese la construcción hipotáctica; a saber, 'espera (sc. un momento), entretanto voy a leer, o a desatar, o a hacer algo'. Así p. ej. Pl., Rud. 719 abi modo, ego dum hoc curabo recte, sin duda de abi modo dum, ego hoc curabo recte.

El paso era tan natural que a veces es difícil decidir si tenemos ante nosotros una construcción paratáctica o hipotáctica. Por ej. en Pl., Bacch. 988: ades dum ego has (sc. tabellas) pellego. Con lo cual se desvanece la aparente antinomia entre el sentido puntual de 'ahora' y el de 'mientras, o mientras que', que adquirió a veces el adverbio y sobre todo la conjunción dum.

Y la gran sorpresa es que una de las formas con dum enclítica remite indefectiblemente a un num (posteriormente nunc), gr. vôv 'ahora'. Me refiero al nondum, que como he dicho no significó más que 'aún no' o 'hasta ahora no', y que por lo tanto se explica perfectamente a partir de *non-num. Ahora bien, hemos visto que el grupo -nn- evolucionó en latín corrientemente a -nd- Y nondum fue una forma de uso sin duda frecuentísimo en todas las épocas, y que ejerció un influjo enorme en una serie de formas semánticamente afines: dūdum < ${ }^{*}$ diūdum (de *iam diūdum), necdum, nullusdum, nihildum. Luego debemos concluir que tanto el -dum enclítico como el dum conjunción y adverbio no fueron más que un desgajamiento del -dum surgido en nondum < *non-dum. Hipótesis apuntada ya por Thurneysen en el Thesaurus, entre las varias sugeridas sobre dum: "uel ex num ( $c f$. nunc), per dissimilationem quam dicimus nasci potuisse non negem".

$\mathrm{Y}$ a la luz de estas conclusiones hay que explicar una serie de adverbios pronominales con final en -nde: inde, exinde, deinde, subinde, unde, aliunde. Adverbios al parecer salidos de unas formaciones en -im, -um como istinc, illim, illinc, hinc, olim, interim, utrinque. De unas formaciones construidas con el elemento o desinencia $-m$, que en germánico, balto y eslavo tuvo además del instrumental otros varios valores, y 
que en latín se especificó sobre todo en un valor separativo, derivado al parecer del instrumental. Lo que hasta ahora no ha podido aclararse es la naturaleza del elemento final -de. Pues los autores suelen creer que ese -de procedió de un elemento ide. -dhe, que en latín y en los dialectos se habría alargado con una $-i(-d h e i)$, de donde *ibei $i b \bar{i} i b i$ (con abreviamiento yámbico) y *ubeī $u b \bar{i} u b i$, umbro pufe (así Stolz Leumann, $H$. Gr.6, p. 482). Pero se ve por un lado que las formas con el supuesto -dhei tienen un sentido locativo claro de 'lugar en donde' ( $i b i$, $u b i)$, mientras que las con -nde suponen un valor ablativo, es decir, de separación. Y por otro lado resulta que la aspirada presenta en latín evolución distinta en -dhei y en -nde. Y por lo demás yo no creo


puesto que lleva siempre una final $-\nu$, que en el lat. -nde nunca se da. A mí pues me parece muy dudoso que el supuesto ide. -dhe dé razón de las formas latinas.

Yo lo que encuentro es que en latín existió la preposición $d \bar{e}$ con función separativa de ablativo. Y como es sabido, las preposiciones en principio fueron adverbios, que se posponían a la palabra afectada: mecum, tecum, secum, nobiscum, uobiscum, prorsus, rursus, sursum, quorsum, aliorsum, quousque, quoad, etc. ${ }^{2}$. Podría pues pensarse si el -de de inde, unde no sería más que un residuo de ese uso originario pospositivo de la preposición, que con el tiempo se antepuso a veces al inde, unde para reforzarle (deinde, exinde). Pero esta hipótesis tiene a su vez el inconveniente de que, frente al inde, unde siempre con $e$ en la posposición, de la preposición dē no se conoce más forma que la con $d \bar{e}$. Lo cual hace muy dudoso que aquélla procediese de ésta. Frente a esto parece claro que en latín existió una partícula -ne al parecer de sentido reforzante. Una partícula atestiguada por el osco inim, y lat. enim 'en efecto, en verdad, a saber, ciertamente, pues' (con sus compuestos etenim, enimuērō). $\mathrm{Y}$ una partícula muy interesante por varias razones. Una el que al parecer fue una variante suya el -na de nam, namque, nempe, quisnam. Y otra el que se ve que admitía un uso enclítico; cf. lat. postne, posne, ponne y umbro ponne, pone. Pues, claro está, a partir de formas como *imne, *umne tuvieron que darse

22 Por cierto que Cicerón, Orat. 45, 154 creyó ingenuamente que se prefirió nobiscum a cum nobis por un eufemismo y para evitar el parecido con cunnus (quia si ita diceretur obscenius concurrerent litterae). Pero naturalmente que la posición de cum se dio en una serie de palabras que no tenían el grupo malsonante cunnus. Es pues claro que la posposición procedía de un uso heredado del ide., del que existen ejemplos en otras lenguas, aunque su especificación en el uso preposicional parece que en parte debió realizarse ya en época muy antigua del ide. 
en latín unas formas como *inne, *unne, de las que a su vez era natural el paso en latín a inde, unde. A mí pues me parece que debe ser ésa la interpretación más verosímil de tales formas.

No sólo esto, sino que el grupo -nd- (o - $m d$ ) se da a veces en latín en ciertas formas del acusativo relativo-indefinido, alargadas con un elemento -do,-dam: quandō / aliquandō / quandōque y quīdam / quemdam / quondam. Ahora bien, ya he indicado que en latín no hay ningún indicio de que existiese una partícula -do, ni como tema independiente ni como enclítica ${ }^{23}$. La que sí se dio fue una partícula -na, probablemente paralela al -ne, como éste con valor reforzante: nam, namque, nempe, utinam, y que como éste admitió también un uso enclítico utinam, quisnam. Ahora bien, es claro que con esa partícula los acusativos del relativo-indefinido tuvieron que dar unas formas como *quemnam, *quom-nam. $\mathrm{Y}$ en latín vemos que el -mn- evolucionó frecuentemente a $-n n->-n d$. Luego deduzco, frente a las dudas de Thurneysen, que el quondam no fue más que otro caso más del cambio -mn->-nd-; y que el -dam de quīdam, cuius-dam, etc. no fue más que una transferencia a todo el paradigma del -dam surgido en el acusativo. Por otra parte, la existencia de un -no de refuerzo está atestiguada en los dialectos por umbro panupei 'quandoque' y arnipo < *adnequod = dōnec; y a lo que creo por el interrogativo num 'acaso', cuando se esperaba contestación negativa (num uidisti 'ciertamente viste'). Creo pues que también el quandō hay que explicarlo de igual manera; es decir, como resultado de un ${ }^{*} q u a m-n \overline{\text {. }}$ Es decir, que en realidad tuvo razón Thurneysen al sospechar, aunque él no encontró pruebas para demostrarlo, que los gerundivos latinos en -ndus salieron de participios medios ide. en -menos >-mnos > -ndus.

El problema que esta explicación plantea a los partidarios de las leyes fonéticas inexorables es que de un mismo grupo el -menos obliga a suponer nada menos que cuatro cambios: el -menos/-minus, el -mnus, el -nnus y el -ndus. Pero ya he indicado que la evolución del mismo sonido en circunstancias aparentemente iguales en variantes diversas fue un fenómeno corriente en todas las lenguas, incluso en un momento dado, y mucho más en la evolución de las lenguas. Desde luego que tanto el -menos/-minus como el -mnus y el -nnus y el -ndus se conservaron inalterables en muchas palabras: femina, lamina; alumnus, Vertumnus, columna; annus/annosus, panna, penna, pinna, canna, etc. Pero esto se debió, no a que cada uno de los cambios se verificase y consumase en un

23 El dudoso dōnicum/dōnec 'hasta que', 'hasta que por fin', ¿no será una alteración de dēni-que (de *dēmique $<$ dēmum) = 'por fin', influido por dum, cum? 
período de cincuenta años, y a que las palabras que no lo sufrieron no existiesen en ese período o no existiesen con la forma presupuesta por el cambio, sino a otras muchas razones. (Cf. sobre esto Actas del $5 .^{\circ}$ Congreso Español de Estudios Clásicos, Madrid 1978, pp. 29-131). ¿Qué por qué en concreto en los gerundivos la $-n n-<-m n-$ se convirtió en -ndus? Pero esto sin duda no tuvo más causa sino que en muchos (en muchísimos) casos el tema verbal llevaba ya otra nasal. A saber, en casos como amo, emo, dēmo, fremo, premo, sūmo, etc.; o como en cano, ceno, conor, maneo, punio, teneo, uenio, etc., o como frendo, fundo, pando, prendo, tondeo, tundo, uendo, etc. Pues naturalmente en tales casos tuvo que producirse el encuentro a corta distancia de dos nasales en posición parecida; con el inconveniente además de que la segunda iba geminada: *amannus, *emennus, *dēmennus, *fremennus, etcétera. No tiene pues nada de extraño que se produjese uno de esos tétanos que en todas las lenguas suelen dar origen a las disimilaciones, y que por lo tanto la forma de las nasales geminadas, que era la en posición más débil (entre otras razones por su posición posterior), se disimilase.

Creo pues que todos los aspectos de la formación quedan explicados a toda satisfacción dentro de esta hipótesis. Hipótesis que, como he dicho, concuerda además con el hecho de que en los verbos radicales o temáticos el sufijo tuvo originariamente la forma -undus, en correspondencia con el $-6 \mu \varepsilon v o \varsigma$ del griego. Un detalle en este aspecto curioso es el umbro anferener 'circumferendi', que supone el secundario -endus. Pero esto entiendo que hay que atribuirlo, no precisamente a que dentro del umbro se hubiese producido el mismo fenómeno -undus $>$ -endus que en latín, sino más bien a que en la época en que surgió el anferener el umbro estaba ya bajo el influjo del latín, y aceptó la forma generalizada en éste. Por lo menos ésa es mi impresión.

Angel Parienti 